\title{
Organizational and Managerial Aspects of Automation in the Internal Accounting of an Enterprise
}

Submitted 11/05/20, $1^{\text {st }}$ revision 10/06/20, $2^{\text {nd }}$ revision 02/07/20, Accepted 30/07/20

\author{
Olga M. Dmytrenko ${ }^{1}$, Olena F. Yarmoliuk ${ }^{2}$, Nataliia V. Kudlaieva ${ }^{3}$, Inna M. \\ Sysoieva $^{4}$, Valentyna V. Borkovska ${ }^{5}$, Olesia A. Demianyshyna ${ }^{6}$
}

\begin{abstract}
:
Purpose: The main purpose of this research is to determine the features of the automation of internal accounting through the prism of organizational, and managerial aspects, as well as the economic benefits of this process.

Design/Methodology/Approach: This study is based on statistics from economic and accounting institutes in order to identify key software products for automation and determine the most optimal prices for them and their diversification depending on the scope.

Findings: The results of the study show that each of the software has its advantages and disadvantages, the combination of which ultimately affects the choice of management of a particular product. In addition, it has been established that there are a number of free programs that can be used by entities with limited financial resources, which will allow them to save a lot of time and optimize their work.

Practical Implications: This study raises the awareness of market participants about the existing areas of internal accounting automation, the key benefits of its implementation and pricing policy. In addition, it confirms that it is possible to choose the program that best meets the individual needs of the enterprise regardless of the amount of available resources for automation and the scope of activities. Therefore, there is no necessity to delay the automation process, but it is better to implement it at the beginning.

Originality / Value: The study emphasizes that the final decision on the direction of automation is made depending on the contextual conditions of the entities, taking into account the stage of the enterprise, available financial resources and scope of activities.
\end{abstract}

${ }^{1}$ Senior Lecturer, Zhytomyr National Agroecological University, Zhytomyr, 10008, Ukraine, E-mail: olga.n.dmitrenko@gmail.com

${ }^{2}$ Associate Professor, Zhytomyr National Agroecological University, Zhytomyr, 10008,

Ukraine, E-mail: radushinskayal@gmail.com

${ }^{3}$ Head of the Department, Yuriy Fedkovych Chernivtsi National University, Chernivtsi, 58012, Ukraine, E-mail: kydlanata@gmail.com

${ }^{4}$ Associate Professor, Vinnytsya Educational-Scientific Institute of Economy of the Ternopil

National Economic University, Vinnytsia, 21017, Ukraine, E-mail: innas1853@ gmail.com

${ }^{5}$ Associate Professor, State Agrarian and Engineering University in Podilia, Kamianets-

Podilskyi, 32300, Ukraine, E-mail: valentinaborkovska@gmail.com

${ }^{6}$ Associate Professor, Pavlo Tychyna Uman State Pedagogical University, Uman, 20300,

Ukraine, E-mail: olesia2710.80@gmail.com 
Keywords: Accounting, automation, software, software rating, software characteristics.

JEL Codes: $M, M 4, M 2$.

Paper Type: Research paper.

\section{Introduction}

The spreading of innovative technologies in all spheres of social and economic life has not missed the field of accounting. Thus, there has been a continuous process of transition of an increasing number of accounting operations to the stage of automated execution in recent decades. It is happening with a gradual decrease in the level of necessity for human intervention. Among other things, this is due to the fact that human mistake is one of the biggest problems of traditional accounting.

At the same time, modern software helps to open the full potential of accountants and financial workers (Potyshniak et al., 2019). It is so because of automation that they can easily make the tedious, time-consuming tasks. In addition, managers significantly increase their reliability, which also increases the level of interest in automation by providing accountants with accurate and up-to-date accounting tools (Zamlynskyi et al., 2019).

However, the process of automation of internal accounting goes with the formation of its key subjects - accountants. The fears about the possibility of their total replacement by modern technology are wrong. It is so because automated program will perform the necessary operations accurately and without errors. Given the above, we can confidently say that the chosen research topic is extremely relevant and relevant, and the rapid emergence of new technologies, including in the accounting field, every year, necessitates its further disclosure, taking into account the latest achievements.

\section{Literature Review}

The study of the available scientific literature concerning the organization and automation of internal accounting allows forming a statement about the high degree of research on this topic. Particularly, Deshpande (2020), notes that many companies focus on old processes when it comes to accounting. So, in their opinion, it is much easier to rely on tables in Excel, transferring them between employees, to update and make changes that have occurred in the process of work, along with a clear system of interaction with managers, which due to the employment of the latter may take days, weeks or months. However, all this hinders the growth of companies. On the other hand, automation of accounting, allows you to open the door to a better reality, to lead 
to successive operations, saving time and forming a much better final result (Deshpande, 2020).

At the same time, Morris (2019), notes that the necessity for automation is a priority in accounting, but the actual definition of automation can vary greatly, as technologies such as Robotic Process Automation, artificial intelligence, machine learning and even Excel-based macros are also considered types of automation (Morris, 2019).

In addition, Lazanis (2020) provides an explanation of the various technologies that can be used to automate accounting, describing that Robotic Process Automation is a technology that mimics human actions to reduce its participation in recurring tasks. An example of such tasks in accounting is the processing of invoices. As for artificial intelligence, it mimics human judgments and behavior on the type of human intelligence and aims to solve certain problems. Machine learning is a type of artificial intelligence and we use it to teach a computer to do work based on experience. The more experience we pass on to him, the more accurate it will be to work with certain automated processes. An important factor is that the above technologies cannot work in tandem (Lazanis, 2020).

Accounting automation, according to Whatman (2020), selects the most manual processes of the accountant and does them automatically, sometimes even instantly. Under such conditions, employees no longer need to create complex files in books and enter countless rows of data, because key formulas are built-in, and countless reports can be created with a few clicks. Today, accounting automation eliminates the least effective aspects of the accountant's work and leaves more time for them to analyze, formulate strategy and ensure interaction between people (Whatman, 2020).

A similar view Hayes (2020), states that accounting automation is a kind of accounting solution that uses artificial intelligence to perform repetitive responsibilities, such as data entry and analysis of important documents.

An example of general automation is the experience of such a large company as NBC Universal, in which most of the automation is carried out through the use of cash applications and the creation of accounts for international cash orders. NBC Universal's Chief Financial Officer, Bob Kurpershoek, says: "The workload is quite large and the processes themselves are standardized. The combination of these two areas of automation significantly increases the return on investment for their implementation, which is positive" (Accountingseed, 2019).

Most finance and accounting professionals, Rana (2020) believe, work with grueling operational tasks and rarely have time to focus on value-added activities. Therefore, there is an increasing need to automate time-consuming processes, which will free up sufficient time for employees to process analytical information, because automation, along with advanced forecasting algorithms will allow professionals to look to the future and guide business to success (Rana, 2020). 
At the same time Half (2019) notes that from manual work to total accounting automation should go through several stages, each of which will be the transition of tasks from human to automated program. The main areas on which automation will focus will be: routine tasks, the implementation of which involves compliance with the algorithm; ensuring compliance; interaction with clients by creating chatbots for contracts and automating the process of preparing documents, as well as forming a strategy where the possibilities of artificial intelligence in terms of analysis far exceed human capabilities, but far inferior in the creative component, which is the prerogative of man alone (Half, 2019).

\section{Research Methodology}

The methodological bases of the study are the works of foreign and domestic researchers, official statistics, on the basis of which conclusions are formed on the areas of accounting automation. Methods of analysis, synthesis, formalization, logical abstraction, theoretical knowledge, monographic, systematization and classification, abstract-logical and others are used.

To evaluate the supply on the market, accounting automation was graded software on a 10-point scale, its key characteristics, price range and level of use depending on different areas of activity.

\section{Empirical Findings}

The accounting process is faced by almost all business entities, because where there is money there is a need to keep them. Thus, the question arises of its effective organization to minimize the time spent on unnecessary operations and increase its accuracy and transparency. In this case, automation comes to the rescue, which actually frees up time for accountants, which they can spend on analytical and control activities.

This, in the end, significantly affects the efficiency of doing business, and therefore encourages managers to turn more and more to automation. In particular, the advantages of accounting automation include specific actions as they aare presented in Figure 1.

So, summarizing all information above, we can conclude that automation has a positive effect on saving time, increasing productivity, accuracy and speed of data retrieval, data storage security, and allows storing accounting information using cloud services, as well as ensuring its integration in real time.

After forming an understanding of the essence of the process of accounting automation, consider the areas in which it can be directed, schematically depicting them with the help of Figure 2. 
Thus, we will consider the detailed specified directions. Let's start with the basic process in the activities of each organization - the purchase process, as its automation provides the company with security and protection of multi-stage processes of access to the system without wasting time and resources arising from the need to view and process documents manually by several stakeholders (Schmidt, 2020).

Figure 1. Advantages of accounting automation

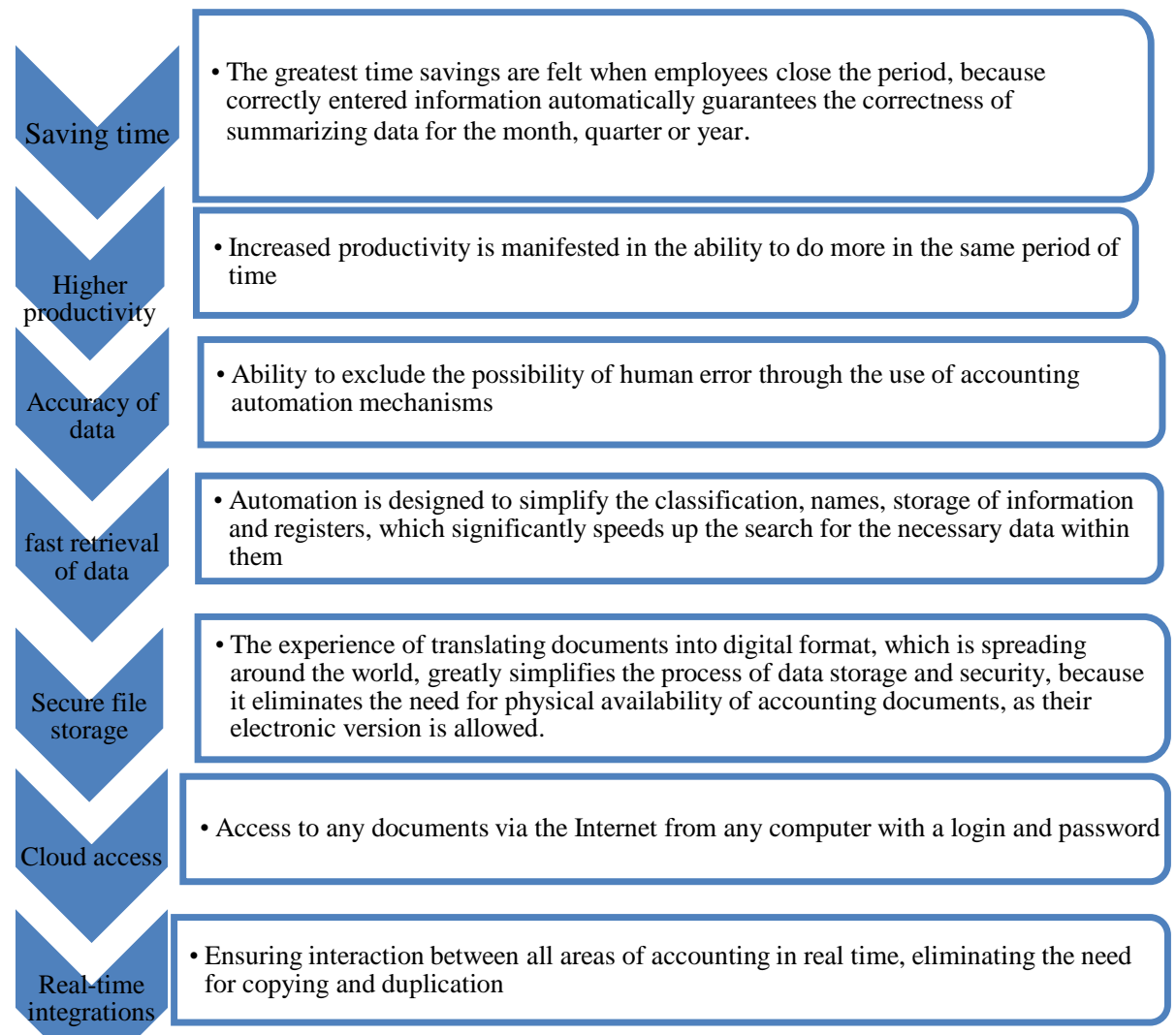

Source: Created by authors on Whatman (2020).

Another area of automation that is critical is reimbursement of travel expenses, as companies can spend hundreds of thousands of hours a year processing data on low travel expenses, which negatively affects overall performance.

In addition, the submission of cost reports is subject to automation, the process of formation and submission of which includes several voluminous stages in the preparation of initial data on costs with the support of receipts to them. Transferring these actions to the digital plane will not only save time, but also free employees from labor-intensive work (Deshpande, 2020). 
Figure 2. Key areas of concentration of automation in internal accounting

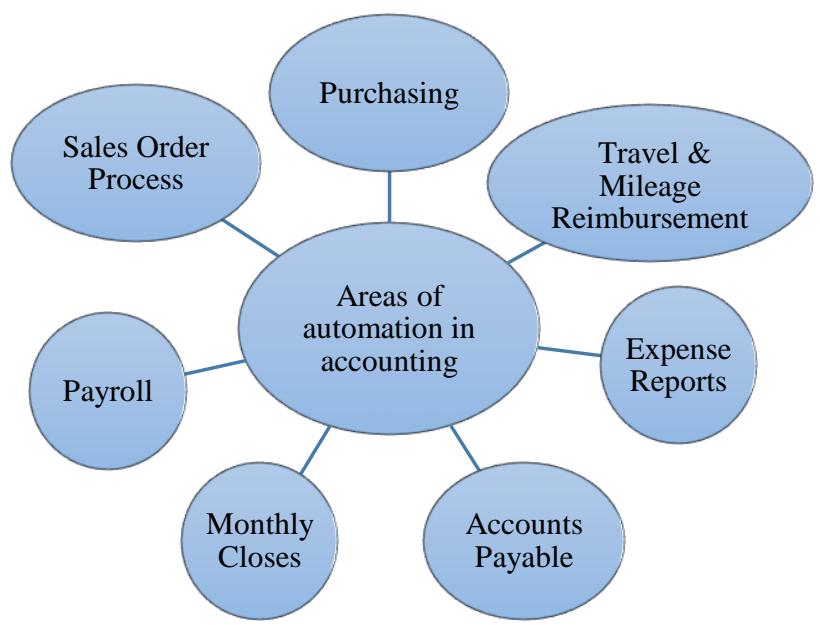

Source: Created by authors on Deshpande (2020) and Schmidt (2019).

The use of automation principles is extremely important when managing accounts payable, in particular in terms of obtaining operational data on the time of ordering deliveries, payment deadlines, as well as tracking the situation with issued invoices, which in turn increases the efficiency of accounts payable.

Equally important for the overall efficiency of accounting is the automation of the process of forming orders from customers, which is expressed in the fact that employees of the company have real-time information about existing orders and the stage of their execution, in order to timely and fully fulfill their obligations in front of buyers.

The positive effects of automation of the payroll process are largely felt in the context of constant legislative changes in the field of wages, because they are all taken into account automatically by the program, as they download new report forms, basic amounts for payroll, etc. This not only frees up an incredible amount of time for the accountant, but also allows him to constantly keep abreast of legislative changes, because information about them usually comes as part of a software update (Deshpande, 2020).

The final direction, which we consider in the process of automation of accounting is the closing of periods, which takes place in almost every company on a monthly basis and usually causes great stress for accountants.

This is confirmed by a survey conducted by Docuware, according to which $90 \%$ of respondents feel pressure from the monthly closing of the period, and only $39 \%$ are satisfied with this process. At the same time, only $28 \%$ of respondents trust the results of the period for their companies and the amount of a certain financial result, which 
puts forward the need to automate this process to one of the first steps in transferring internal accounting to the automated plane (Deshpande, 2020).

After studying the positive aspects of accounting automation, as well as researching the probable directions of its implementation, the company's management has a question about the choice of software with which this process will be carried out, because every year their number is constantly growing. In this case, each of the proposed software is best suited to one or more activities and is not suitable for others. Therefore, we will conduct a study of existing programs in the market of accounting automation, depicting their gradation by the number of points from users. We will issue results by means of Figure 3.

Figure 3. Accounting Software ranking in 2020

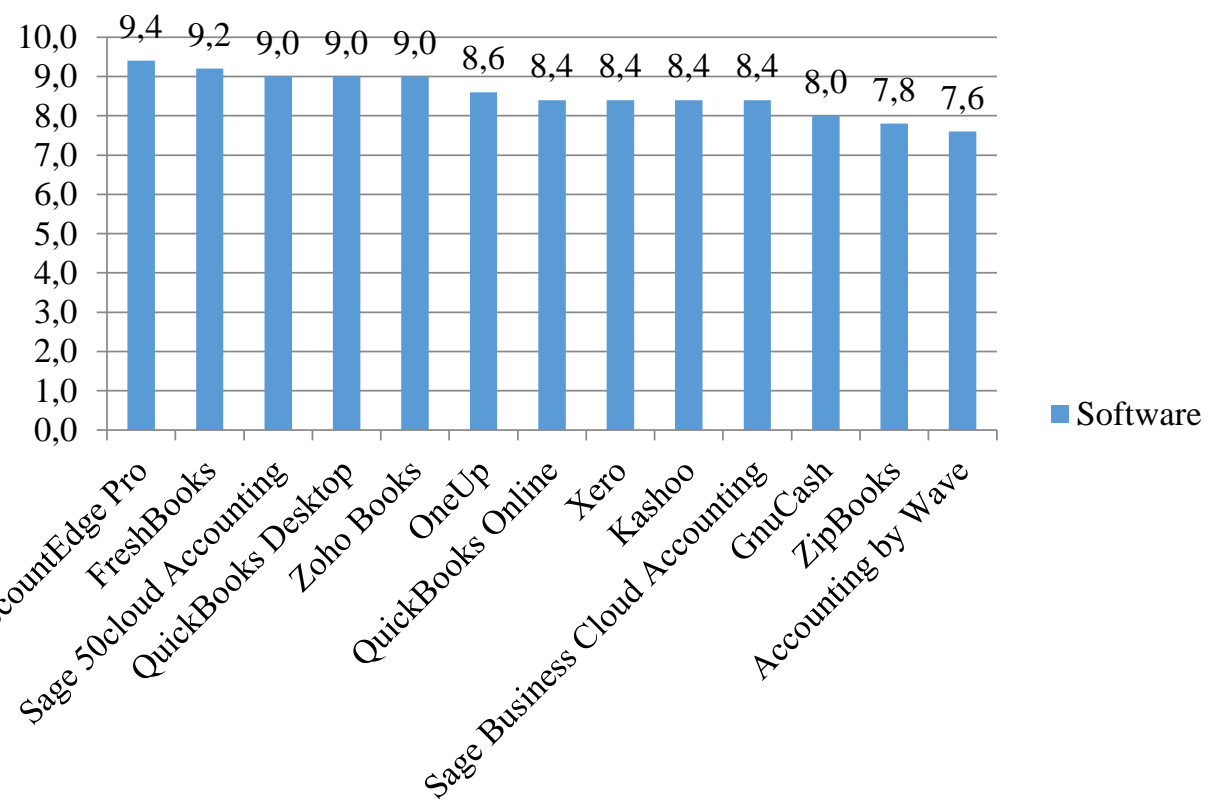

Source: Created by authors on Girsch-Bock (2020).

Analyzing the data shown in the figure, we can conclude that the most popular software is Accounting Edge Pro, which was awarded 9.4 points out of 10 possible. In addition, the rating is headed by Fresh Books - 9.2 points; Sage 50cloud Accounting 9.0; Quick Book Desktop - 9.0, and Zoho Books - 9.0 points. The lowest number of points among the above ranking is Gnu Cash - 8.0; ZipBooks - 7.8 and Accounting by Wave - 7.6 points.

Let's consider in more detail characteristic features and key advantages of some of the offered software, having issued results by means of Table 1 . 
Table 1. Detail characteristic features and key advantages of some of the offered software

\begin{tabular}{|c|c|c|}
\hline Software & Spheres of usage & Key features \\
\hline 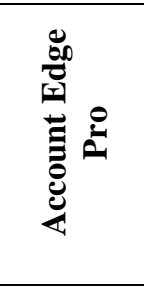 & $\begin{array}{l}\text { Suitable for small and } \\
\text { medium-sized } \\
\text { businesses. Offers } \\
\text { remote access, making } \\
\text { it best suited for online } \\
\text { shopping }\end{array}$ & $\begin{array}{l}\text { Invoicing with the ability to track their payment, } \\
\text { payroll, inventory management. Availability of the } \\
\text { "Contacts" service for tracking information about } \\
\text { key contractors of the company by forming a single } \\
\text { database. Mobile application available. }\end{array}$ \\
\hline$\frac{n}{8}$ & $\begin{array}{l}\text { Best for entrepreneurs, } \\
\text { freelancers, lawyers and } \\
\text { accountants working } \\
\text { online }\end{array}$ & $\begin{array}{l}\text { Local and network versions, the presence of a double } \\
\text { entry in the program, the ability to connect to a bank } \\
\text { account, the program is extremely easy to use. There } \\
\text { is also a mobile application, but there is no payroll } \\
\text { function, which is connected using the additional } \\
\text { service Gusto Payroll }\end{array}$ \\
\hline 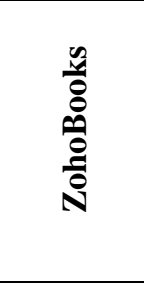 & $\begin{array}{l}\text { Best for entrepreneurs, } \\
\text { freelancers and those } \\
\text { who are just starting a } \\
\text { business }\end{array}$ & $\begin{array}{l}\text { Availability of step-by-step instructions for all } \\
\text { actions in the program, actual to new business, the } \\
\text { ability to manage inventory, automate workflows, } \\
\text { cost tracking, project management, the ability to } \\
\text { create your own invoices. The disadvantage is the } \\
\text { inability to calculate the salary, as well as the } \\
\text { inability to use additional programs. }\end{array}$ \\
\hline 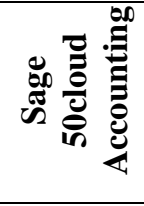 & $\begin{array}{l}\text { Best for small and } \\
\text { developing business. } \\
\text { Suitable for retail use. }\end{array}$ & $\begin{array}{l}\text { Ability to connect bank accounts, track business } \\
\text { expenses, wide opportunities for inventory, the } \\
\text { ability to accept online payments. Availability of a } \\
\text { mobile application, as well as integration with } \\
\text { Microsoft } 365 \text {. }\end{array}$ \\
\hline$\underbrace{\frac{0}{0}}$ & $\begin{array}{l}\text { Suitable for startups, } \\
\text { freelancers and owners. } \\
\text { Does not suitable for } \\
\text { small businesses in the } \\
\text { phase of development. }\end{array}$ & $\begin{array}{l}\text { Offers almost all accounting functions, including } \\
\text { accounts payable and receivable management, as } \\
\text { well as drawing up a business plan. Financial and } \\
\text { accounting reports, depreciation are well presented. } \\
\text { Salary functions are not fully implemented. The } \\
\text { application is free. }\end{array}$ \\
\hline $\begin{array}{l}\frac{n}{0} \\
0 \\
0 \\
0\end{array}$ & $\begin{array}{l}\text { Ideal for small the } \\
\text { owners of business, } \\
\text { including freelancers, } \\
\text { consultants and private } \\
\text { entrepreneurs }\end{array}$ & $\begin{array}{l}\text { There is bank account connection for a single } \\
\text { account, unlimited customer tracking and sales } \\
\text { management, including receivables management. } \\
\text { Available in both free and paid access, depending on } \\
\text { the list of features. }\end{array}$ \\
\hline
\end{tabular}

Source: Created by authors on Girsch-Bock (2020), McQuarrie (2020) and Williams et al. (2020).

In addition to the above advantages of software, the choice of their specific type is influenced by the pricing policy. Therefore, we analyze the minimum price for various software presented on the world market using Figure 4.

Analyzing the data shown in the figure, we can conclude that the lowest price per month of using the program is around \$ 9 for programs such as Xero, Zoho Books and 
Kash Flow. At the same time, the most expensive is the use of Sage 50 cloud Accounting - \$23.25 per month, as well as Accounting Edge Pro and Kashoo, \$ 12.4 and $\$ 16.58$ per month.

At the same time, there are a number of programs that are free to access. Among the best free programs are: ZipBooks, Money Manager Ex, GnuCash, TurboCASH, Wave, $\mathrm{NCH}$ Express Invoice, VT Cash Book, Invoice Expert Lite Edition, Adminsoft Accounts and QuickFile (Williams et al., 2020). Of course, in connection with the granting of free use in these programs is not implemented all the functionality that an accountant needs, but with the right combination of several of them you can achieve maximum automation for free, which is especially true for small businesses and firms just starting out activity.

Figure 4. The minimum price for software for accounting automation

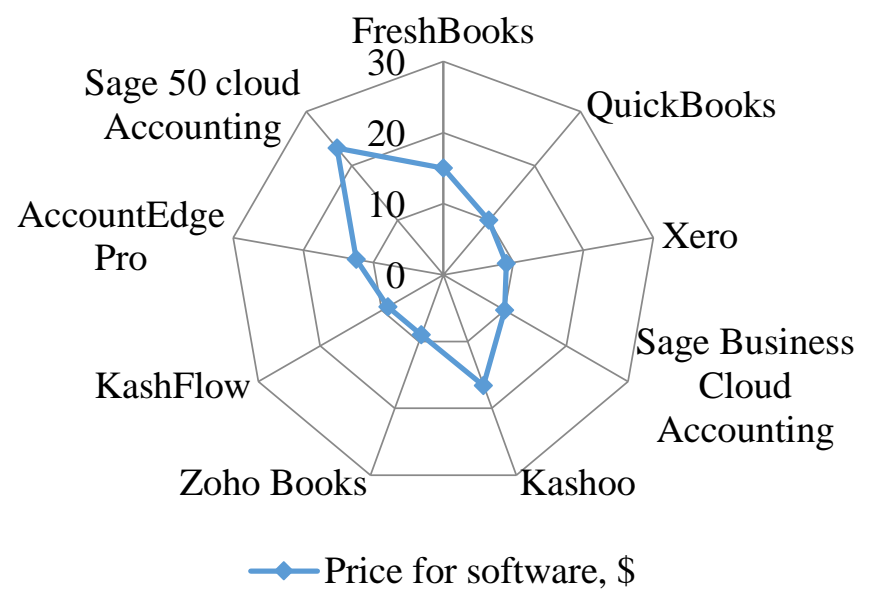

Source: Created by authors on Johnson (2020) and Williams et al. (2020).

In addition, all software used to automate accounting is divided into three types:

- commercial software for accounting, presented in the form of both simple programs and in the form of full software services, which offer full functionality for accounting. There are also many optional modules to choose from. This software is usually available for download as an application, either by subscribing to Saas (Software as a service) or from the cloud (Girsch-Bock, 2020);

- enterprise resource planning (ERP) software is typically used by large companies and is expensive (Girsch-Bock, 2020);

- Specialized accounting programs that were popular about 20 years ago, but disappeared from offices due to the large number of functions that are now used through commercial accounting programs. The decrease in their level of 
use is associated with problems in the work, as well as lack of integration with other programs (Girsch-Bock, 2020).

In addition, the choice of specific software is influenced by the scope of the entity. Consider the level of use of various software in enterprises represented by such areas as industrial manufacturing, automotive, utilities, public / government, retail, consumer packaged goods manufacturing and global average using Figure 5.

Figure 5. The level of usage of various software depending on the sphere of activity

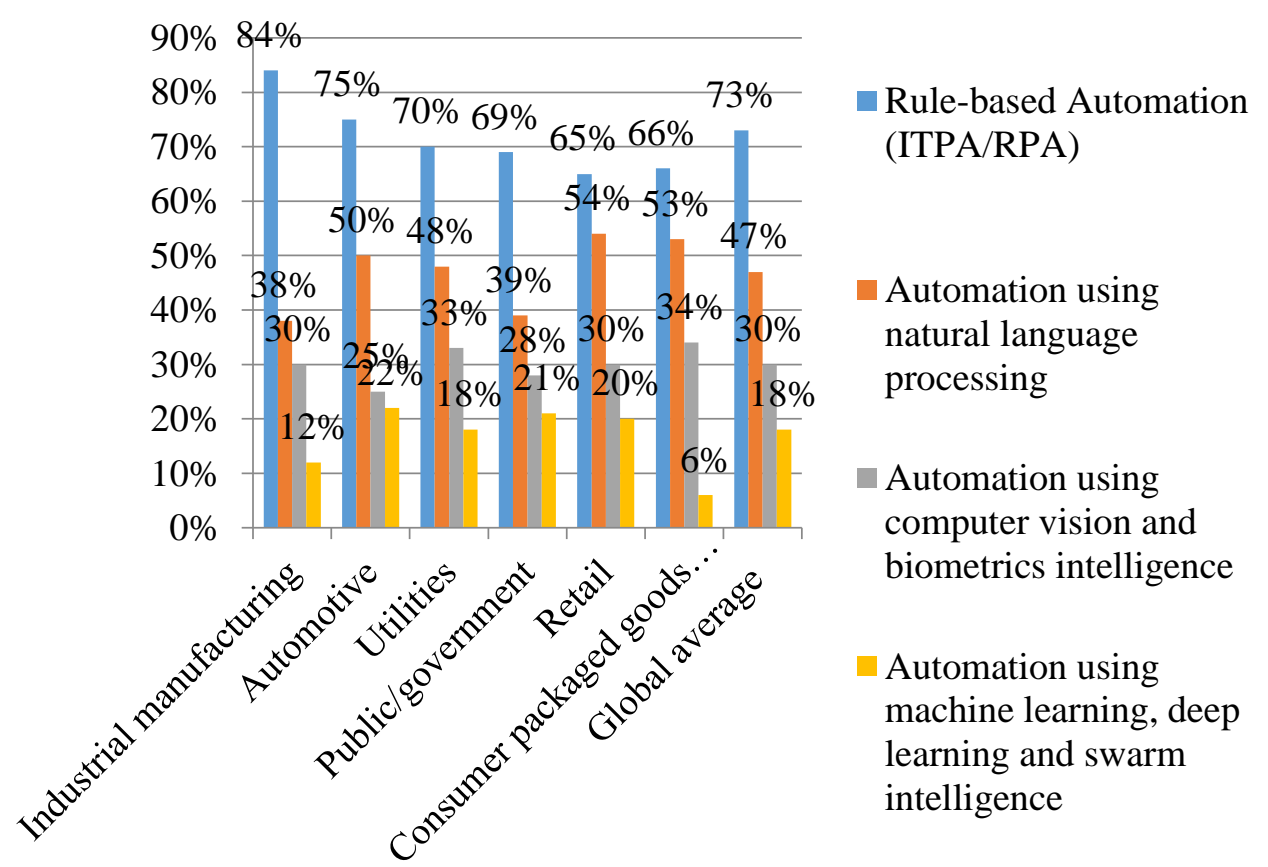

Source: Created by authors on Capgemini (2018).

So, being based on the data shown in the figure, we can conclude that the vast majority of entities for automation use Rule-based Automation, the level of application of which ranges from 60 to $84 \%$, followed by Automation using natural language processing - used at the level of $54-38 \%$, as well as Automation using computer vision and biometric intelligence - $34-25 \%$. The least enterprises carry out automation due to Automation using machine learning, deep learning and swarm intelligence - at the level of $22-6 \%$. It should be noted that several approaches to automation can be used within one entity.

\section{Discussion and Conclusions}

Based on the study, it was found that the automation of accounting has an extremely large positive impact on the activities of enterprises. So, the advantage of this process 
include saving time, increasing productivity, accuracy and speed of data retrieval, security of data storage, as well as allow storing accounting information using cloud services, as well as provides its integration in real time.

Therefore, it is natural that every year more and more managers decide to automate accounting in the enterprise, replacing routine work with an automated program. In this case, within the organization can be automated as the entire accounting process and some of its sectors. In particular, such sectors include: purchases, reimbursement of travel expenses, cost reports, depreciation and wages, monthly closures, etc.

In addition, significant difficulties arise at the stage of software selection from the existing wide list. The study comes to help in this case. It is about information about the key benefits of each of them, the range of functions that are implemented in them, as well as the cost of their usage. The combination of these factors allow choosing the most optimal direction of automation, depending on the specific needs of the subject. At the same time, the choice of automation method is also influenced by the scope of the enterprise, because, as a rule, each program in the functionality of each program has its own specific commands that are suitable for a particular area.

As we can see, automation is on the one hand a complex and time-consuming process at the stage of its implementation, and on the other hand, we can confidently say that it will pay for itself in the near future.

So, the study contains information about the essence of automation of internal accounting, as well as the benefits of its implementation. In addition, the directions of accounting automation are studied, highlighting such areas as: the formation of orders from customers, the issuance of invoices, payroll and depreciation, submission of expense reports, etc.

In addition, the most popular accounting programs are analyzed, reflecting their gradation. Based on the study, it was found that the highest score was given to software such as Accounting Edge Pro, as well as Fresh Book, Sage 50cloud Accounting, Quick Book Desktop and Zoho Books. On the other hand, the lowest scores in our ranking were received by such programs as GnuCash, ZipBooks and Accounting by Wave.

The choice of a particular one is greatly influenced by the functionality they offer, as well as the price you have to pay for it. Therefore, we have explored the key characteristics of the proposed programs, as well as identified the subjects for whom they are most suitable. In addition, the current software pricing policy, which ranges from $\$ 9$, was analyzed and reaches 16.58 dollars per month, as well as a list of programs to which access is provided free of charge.

So, the study found that the use of accounting automation has an extremely large positive impact on the activities of the entity. At the same time, the transfer of 
accounting to the digital plane in no way reduces the role of a qualified accountant in this process, but only increases the accuracy, speed and efficiency of his actions.

\section{References:}

Accountingseed. 2019. When will Accounting been Automated. Available at: https://www.accountingseed.com/2019/07/11/when-will-accounting-be-automated/.

Capgemini. n./d. Capgemini Research Institute. Available at: https://www.capgemini.com/research-institute/.

Deshpande, A. n./d. Accounting automation: Building scalable financial ops. Available at: https://www.frevvo.com/blog/accounting-automation/.

Girsch-Bock, M. 2020. The Top 10 accounting software for small businesses in 2020. The Blueprint. Available at: https://www.fool.com/the-blueprint/accounting-softwarereviews/.

Half, R. 2019. What you need to know about accounting automation. Available at: https://www.roberthalf.com/blog/the-future-of-work/what-you-need-to-know-aboutaccounting-automation.

Hayes, K. 2020. Accounting automation: Understand how it optimizes your business. Select Hub. Available at: https://www.selecthub.com/enterprise-resourceplanning/accounting/accounting-automation/.

Johnson, S. 2020. The best accounting and invoice-generating software. Business.com. Available at: https://www.business.com/categories/accounting-software/.

Lazanis, R. 2020. Accounting Automation: The 2020 Annual Guide. FutureFirm. Available at: https://futurefirm.co/accounting-automation/.

McQuarrie, K. 2020. The Best Small-Business Accounting Software of 2020. Business org. Available at: https://www.business.org/finance/accounting/best-small-businessaccounting-software/.

Morris, K. 2019. What is accounting automation, really? Blackline Magazine. Available at: https://www.blackline.com/blog/financial-close/what-is-accounting-automation/.

Potyshniak, O., Dobuliak, L., Filippov, V., Malakhovskyi, Yu., Lozova, O. 2019. Assessment of the effectiveness of the strategic management system of investment activities of companies. Academy of Strategic Management Journal, 18(4), 1-5.

Rana, K. 2020. How automation is disrupting finance and accounting industry. Express Computer. Available at: https://www.expresscomputer.in/rpa/how-automation-isdisrupting-finance-and-accounting-industry/56774/.

Schmidt, D. 2019. Top 10 processes enterprises can automate using RPA. TechNative. Available at: https://www.technative.io/top-10-processes-enterprises-can-automateusing-rpa/.

Whatman, P. 2020. 8 excellent benefits of accounting automation. Spend Journal. https://blog.spendesk.com/en/accounting-automation.

Williams, M., DeMuro, J., Tumer, B., Marshall, C., Clymo, R. 2020. Best accounting software in 2020: free and paid versions to manage accounts. Techradar. Available at: https://www.techradar.com/uk/best/best-accounting-software.

Zamlynskyi, V., Zerkal, A., Antonov, A. 2019. A conceptual framework to apply financial engineering at the enterprise. Baltic Journal of Economic Studies, 5(1), 68-74. https://doi.org/10.30525/2256-0742/2019-5-1-68-74. 